J. Asiat. Soc. Bangladesh, Sci. 46(2): 133-141, December 2020

\title{
TEMPORAL VARIABILITY, TRENDS OF CLIMATIC VARIABLES AND DROUGHT ANALYSIS OF RAJSHAHI AND SYLHET DISTRICT, BANGLADESH
}

\author{
FATAMATUJ SUNNY, MD. SELIM MIAH, MD. YOUNUS MIA* \\ AND RUKSANA HAQUE RIMI \\ Department of Environmental Science and Resource Management, Mawlana Bhashani \\ Science and Technology University, Tanagil-1902, Bangladesh
}

\begin{abstract}
The study was conducted to quantify the change of selected climatic variables (rainfall, relative humidity, maximum and minimum temperature) over 50 years at Rajshahi and Sylhet districts in Bangladesh. Annual, seasonal, and monthly climatic data comparisons have been executed between 1968-1992 and 1993-2017 through trend analysis. The Mann-Kendall statistic and Sen's Slope model were used to reveal the trends and estimate the magnitude of change respectively. Prediction of the climatic variable of 10 years (2018-2027) was made based on the ARAR algorithm using MaxStat Pro software. Rainfall data were used to analyze drought by using climatic indices (De Mortone Aridity Index, IdM; Seleaninov Hydrothermic Index, IhS; Donciu Climate Index, IcD). Average rainfall was decreasing dramatically in monsoon season at Rajshahi and in both premonsoon and monsoon seasons at Sylhet. The negative change of average rainfall in the monsoon at Rajshahi from 1968-1992 to 1993-2017 was found 29.17 mm. The maximum temperature was increasing in all seasons in both Rajshahi and Sylhet. Annual Mannkendall trend test and Sen's slope revealed that relative humidity was decreasing and maximum temperature was increasing significantly at Sylhet for the period 1993-2017. At Rajshahi, during 1968-1992, relative humidity was increasing by $0.247 \%$ per year, and minimum temperature was decreasing $0.049^{\circ} \mathrm{C}$ per year. Rainfall was decreasing insignificantly in both time scales. ARAR algorithm predicted that average maximum temperature might become comparatively higher than the previous 50 years. 1992 and 2010 were identified as drought years from all climatic indices, and 1969, 1981, and 1997 as excessive wet years at Rajshahi. No drought events were identified during 1968-2017 at Sylhet and the year 2017 to be an excessively wet year. IhS predicted 2020, 2025, and 2027 as drought years and 2024 as an excessive wet year at Sylhet.
\end{abstract}

Key words: Climate change, Trend analysis, Rainfall, Temperature, Relative humidity, Drought analysis.

\section{Introduction}

The Inter-Governmental Panel on Climate Change (IPCC) characterizes environmental change as an adjustment in the condition of the atmosphere that can be recognized (e.g., using statistical tests) by changes in the mean and additionally the changeability of its

*Corresponding author: <mdmia1998@gmail.com>. 
properties and that continues for an expanded period, ordinarily decades or more (Solomon et al. 2007). Changes in atmospheric condition and climate have critical effects on the society (Karl et al. 2008). Variability of temperature, rainfall, and relative humidity are significant influencing factors for studying climate variability and extremes (Fahad et al. 2015). Bangladesh, a South-Asian country, is one of the most climate vulnerable states in the world (Rajib et al. 2012). According to Bangladesh Meteorological Department (BMD) data, the average maximum temperature has an increasing trend at a rate of $0.29^{\circ} \mathrm{C}$ per century but the rainfall is decreasing at a rate of $8.8 \mathrm{~mm}$ over the north-western region (Bhuyan et al. 2018)

Knowing the nature and extent of conceivable climate change at Sylhet and Rajshahi is crucially essential for individuals, stakeholders, and policymakers to adapt appropriate measures. For instance, accurately predicting rainfall trends can play a vital role in a country's potential economic development.

Time series analysis and forecasting have become a significant tool in numerous applications in meteorology and other environmental areas to understand different phenomena, like rainfall, humidity, temperature, draught, etc. (Nury et al. 2013). ARAR algorithm is one of the most widely used time series forecasting methods. The ARAR algorithm applies memory shortening transformation and fits the autoregressive model to the transformed data. It is used to predict future data from existing sequence data. This algorithm is the adaptation of the ARARMA algorithm and had functioned better in a wide range of real data sets (Miswan et al. 2016).

Globally many countries are vulnerable to drought due to climate change and other natural conditions (Wilhite 2000). The rainfall distribution throughout the region and year is non-uniform. This non-uniform rainfall very often causes droughts in every year (Keka et al. 2012). According to the NASA's Tropical Rainfall Measuring Mission (TRMM) data, the minimum rainfall zone was Rajshahi in summer monsoon during 2001-2010 (Bhuiyan et al. 2018). The temperature of this region is comparatively higher than other regions in Bangladesh. Thus, the Rajshahi region is vulnerable to drought conditions. On the other hand, Sylhet experiences the highest rainfall in Bangladesh and has susceptibility to heavy-rainfall and flash floods. Though the drought has attracted less scientific attraction than flood or cyclone, several authors found that the impact of drought can be more defenseless than flood and cyclone (Shahid and Behrawan 2008). For instance, the loss of 1978/79 drought was greater than the loss of flood in 1974 (Paul 1998). Rice production losses in the drought of 1982 were 50 percent more than the losses that occurred due to the flood in the same year (Selvaraju et al. 2006). 
For ease of calculation, investigators frequently use the De Mortone Aridity Index (IdM) for identifying susceptibility to drought conditions (Botzan et al. 1998). We used different climatic indices; De Mortone Aridity Index (IdM), Seleaninov Hydrothermic Index (IhS) and Donciu Climatic Index (IcD) .

According to TRMM information, the minimum rainfall zone was Rajshahi in South Asia (Bhuiyan et al. 2018). On the other hand, Sylhet meets the highest rainfall in Bangladesh.

The study of drought trends is extremely critical as it is related to food security and the management of scarce water resources, which becomes critical in case of drought events. Our present study helps to identify the change of climatic variable (rainfall, temperature and relative humidity), understanding drought at Rajshahi and heavy rainfall at Sylhet using past rainfall performance. Further, the results may help in planning to take necessary actions to manage regional drought and reduce the adverse impacts of drought and heavy rainfall across Rajshahi and Sylhet districts of Bangladesh. The present study was aimed at assessing monthly, seasonal and annual climatic variables (rainfall, temperature and humidity) through trend analysis and prediction of the near future (10 years) changes in particular climatic variables.

\section{Materials and Methods}

Study area: This study was conducted at Rajshahi and Sylhet Districts. Geographically Rajshahi is situated within Barind Tract and lies $23 \mathrm{~m} \mathrm{(75} \mathrm{ft)} \mathrm{above} \mathrm{sea} \mathrm{level.} \mathrm{The} \mathrm{city} \mathrm{is}$ located on the alluvial planes of the Padma River. Rajshahi sits between $24^{\circ} 37^{\prime}$ north latitude and $88^{\circ} 70^{\prime}$ east longitude. Sylhet district lies on $21 \mathrm{~m}$ above sea level in the north-eastern part of Bangladesh and sits between $24^{\circ} 90^{\prime}$ north latitude and $91^{\circ} 88^{\prime}$ east longitude on the River Surma bank. Fig. 1 shows the locations of these two districts.

Study materials and Data collection: The research was carried out on the basis of climatic data analysis. The climatic data were collected from the Bangladesh Meteorological Department (BMD). Daily maximum temperature $\left({ }^{\circ} \mathrm{C}\right)$, minimum temperature $\left({ }^{\circ} \mathrm{C}\right)$, relative humidity $(\%)$, and rainfall $(\mathrm{mm})$ data for the period $1968-2017$ (i.e., 50 years) were used in this study. To maintain the continuity the gaps were filled up by the long-term average values of the existing days of the month for each parameter. Secondary data and relevant information were collected from national and international journals, books, thesis and earlier research papers.

Data processing and analysis: After gathering the necessary data, all collected data were arranged, classified, and analyzed. MS Excel was used for statistical analysis of the data 
and making graphs. The map for location of the BMD stations was made by Arc GIS (version 10.3). The annual average, seasonal average, and monthly average of climatic parameters (rainfall, temperature, and relative humidity) of Sylhet and Rajshahi were calculated to analyze the variability of climatic parameters and compare at the change rate of the climatic variable of these districts. The software named MaxStat Pro (version 3.60) was used for the prediction utilizing the ARAR algorithm.

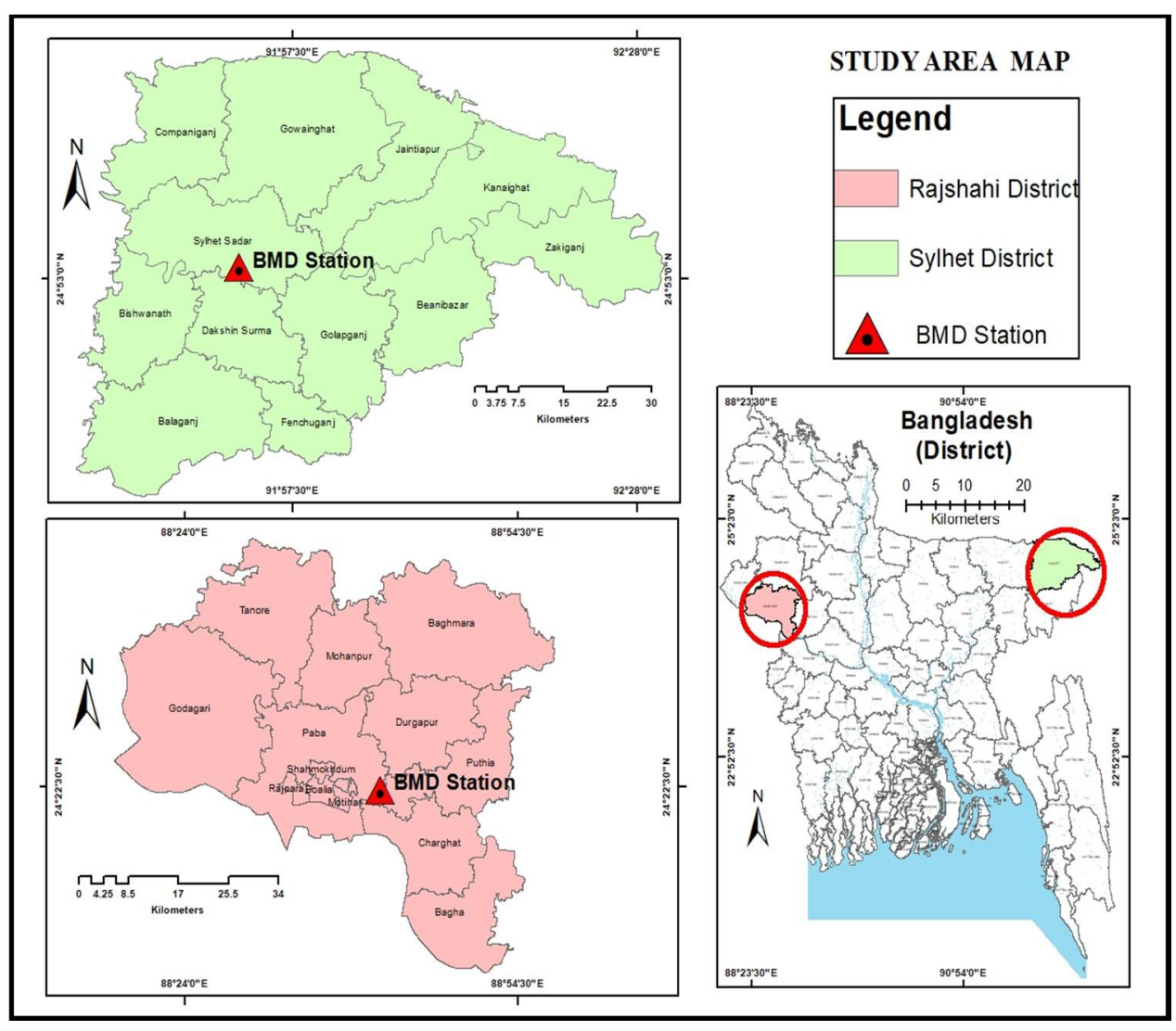

Fig. 1. Location of BMD stations of Rajshahi and Sylhet District.

Mann-kendall analysis: Trend analysis is the prediction of future outcome by using historical results. The increasing or decreasing trend of all the independent weather parameters (e.g., annual and seasonal temperature, rainfalls etc.) was statistically examined in two phases. The first one was the using of non-parametric Mann-Kendall test and the second one was the nonparametric Sen's slope estimator. The increasing or 
decreasing trend was tested based on normalized test statistics $(Z)$ value. When $Z$ is positive, the trend is said to be increasing, and when $\mathrm{Z}$ is negative, it is said to be decreasing. The trend's slope gives the annual rate and direction of change (Kendall 1995). The Mann-Kendall trend test is a non-parametric way of identifying trends in data collected over time series. Mann-Kendall Statistic (S) is given by,

$\mathrm{S}=\sum \sum \operatorname{sign}\left(X_{i}-X_{j}\right)$

here, $i=2,3, \ldots, \mathrm{n} ; \mathrm{j}=1,2,3, \ldots, \mathrm{i}-1$ and

$\operatorname{sign}\left(X_{i}-X_{j}\right)=\left\{\begin{array}{c}1, \text { if }\left(X_{i}-X_{j}\right)>0 \\ 0, \text { if }\left(X_{i}-X_{j}\right)=0 \\ -1, \text { if }\left(X_{i}-X_{j}\right)<0\end{array}\right.$

For a sample size $>10$, a normal approximation to the Mann-Kendall test may be used. For this, a variance of $\mathrm{S}$ is obtained as,

$\mathrm{V}(\mathrm{s})=\frac{n(n-1)(2 \mathrm{n}+1)-\sum t_{p}\left(t_{p}-1\right)\left(2 t_{p}+5\right)}{18}$

Here, $\mathrm{p}=1,2, \ldots ., \mathrm{q}$

Where $t_{p}$ is the number of ties for the $\mathrm{p}$ th value and $\mathrm{q}$ is the number of tied values. Then standardized statistical test is computed by:

$\operatorname{sign}\left(X_{i}-X_{j}\right)=\left\{\begin{array}{l}\frac{s-1}{\sqrt{V(s)}}, \text { if } S>0 \\ 0, \text { if } S=0 \\ \frac{s-1}{\sqrt{V(s)}} \text { if } S<0\end{array}\right.$

The magnitude of the trend was estimated by Sen's slope method (Sen 1968), which was proceeded by calculating the slope as a change in measurement per change in time,

$Q^{\prime}=\frac{X_{t \prime}-X_{t}}{t^{\prime}-t}$

Where, Q' is the slope between data points $X_{t}$, and $X_{t}, X_{t}$, is the data measurement at time t' and $X_{t}$ is the data measurement at time t. Sens slope estimator is simply given by the median slope,

$B= \begin{cases}Q^{\prime}{ }_{\frac{N+1}{2}}, & N \text { is odd } \\ \frac{i}{2}\left(Q_{\frac{N}{2}}^{\prime}+Q_{\frac{N+2}{2}}^{\prime}\right), & N \text { is even }\end{cases}$ 
Where, $\mathrm{N}$ is the number of calculated slopes. A positive value of $\mathrm{B}$ indicates an increasing trend, and a negative value indicates a decreasing trend in the time series. In this study, to represent the confidence level $* * *, * *, *$ and + signs have been used to represent $100 \%, 99 \%, 95 \%$, and $90 \%$ levels of confidence, respectively.

The Auto-regressive auto-regressive (ARAR) prediction method: The ARAR algorithm approach to modeling time series $\left\{S_{t}\right\}$ is described as one of the following three memory types: long memory, short memory, and no memory. A long-memory series is nonstationary due to trends or cycles. A short-memory series is a stationary and a no-memory series is a white noise. The memory-shortened series can be described as follows:

$S_{t}=\mathrm{v}_{0 t}+\mathrm{v}_{1 t-1}+\cdots+\mathrm{v}_{k t-k} \cdots \cdots$

Where, $\mathrm{S}$ is denoted as the sample means of $S_{1}, \ldots, S_{T}$ is the memory-shortened series, $t$ is $1, \ldots, T$ andv $v_{0}, v_{1}, \ldots v_{k}$ is the coefficients of memory-shortening filter (Shitan and Ng., 2015). If the alternative long-memory or moderately long-memory is chosen, then the transformed series $\left\{S_{t}\right\}$ is again checked. If it is found to be long-memory or moderately long-memory, then a further transformation is performed. The process continues until the transformed series is classified as a short memory. The Autoregressive model is fitted using the model as below,

$X_{t}=\lambda_{1} X_{t-1}+\lambda_{l 1} X_{t-l 1}+\lambda_{l 2} X_{t-l 2}+\cdots+Z_{t}$

Where, $\left\{Z_{t}\right\} \sim \mathrm{WN}\left(0, \sigma^{2}\right), l_{1}, l_{2}, l_{3}$ is lag values, $\lambda_{j}$ is coefficient and $\sigma^{2}$ is white noise variance (Brockwell and Davis, 2016).

Yearly drought analysis by the climatic indices: To analyze drought, the meteorological drought analysis method was adopted. Yearly drought analysis was performed by four climatic indices. The climatic indices used are De Mortone Aridity Index, IdM; Seleaninov Hydrothermic Index, IhS; and Donciu Climate Index, IcD. With the help of annual rainfall assurance (A \%), yearly drought analysis was performed by the climatic indices. The correlation established between the assured rainfall (A \%) for years and climatic indices provide the polynomial expression, statistically very significant. It has quantified a very significant correlation between annual rainfall assurance (A \%) and climatic indices using a logarithmic expression, which is shown in Table 1 (Keka et al. 2012). 
Table 1 Climatic indices.

\begin{tabular}{lcc}
\hline Climatic Index & Symbol & Mathematical Function \\
\hline Mortone Aridity Index & IdM & IdM $=-7.3566 \ln \mathrm{A}+58.037$ \\
Seleaninov Hydrotheremic Index & $\mathrm{IhS}$ & $\mathrm{IhS}=-0.4006 \ln \mathrm{A}+3.1001$ \\
Donciu Climate Index & $\mathrm{IcD}$ & $\mathrm{IcD}=-24.269 \ln \mathrm{A}+191.17$ \\
\hline
\end{tabular}

The data registered in the meteorological stations were used for the calculation of the climatic indices. The annual rainfall assurance (A \%) was calculated in the following way: (i) the average rainfall of all years was determined (ii) percentage of rainfall for every year of average rainfall was determined (iii) deducting percentage value from 150 the annual rainfall assurance (A \%) was found. By putting the value of A in each climatic index equation, each climatic index's value was determined. By comparing the value of climatic indices with Table 2, the yearly drought analysis was performed (Keka et al. 2012).

Table 2. Value of interpretation limits for climatic indices.

\begin{tabular}{lccc}
\hline \multirow{2}{*}{ Characterization } & \multicolumn{3}{c}{ Climate Index } \\
\cline { 2 - 4 } & IdM & IhS & IcD \\
\hline Excessive rainy & $>40$ & $>2$ & 110 \\
Very rainy & $33-40$ & $1.6-2$ & $100-110$ \\
Rainy & $29-33$ & $1.4-1.6$ & $95-110$ \\
Medium & $25-29$ & $1.3-1.4$ & $80-95$ \\
Droughty & $24-25$ & $1.1-1.3$ & $70-80$ \\
Very droughty & $23-24$ & $1.0-1.1$ & $65-70$ \\
Excessive droughty & $<23$ & $<1.0$ & $<65$ \\
\hline
\end{tabular}

\section{Results and Discussion}

The annual average maximum temperature was increasing with $0.005^{\circ} \mathrm{C}$ and $0.030^{\circ} \mathrm{C}$ per year in the trend of 1968-1992 and 1993-2017, respectively at Rajshahi. The trend of 1968-1992 and $1993-2017$ had an increment rate with $0.024^{\circ} \mathrm{C}$ and $0.048^{\circ} \mathrm{C}$ per year respectively at Sylhet. According to Basak et al. 2013, the yearly average maximum temperature increased at the rate of $0.007^{\circ} \mathrm{C}$ in the north-western region and $0.022^{\circ} \mathrm{C}$ at eastern region of Bangladesh during the period of 1976-2008, which supports our findings. 2024 may be going to experience the highest average maximum temperature, $32.4^{\circ} \mathrm{C}$, at Rajshahi over the last 60 years. Therefore, our findings suggest that the climate 
has become warmer both at Sylhet and Rajshahi in recent years, and warming will continue in the future too.

Rainfall trend in monsoon decreased at Rajshahi but increased in pre-monsoon. A decrease in monsoon rainfall may be a threat to agricultural production at Rajshahi. The annual rainfall of Rajshahi station had a significant negative trend in the study of Bari et al. 2016, which is analogous to the findings of this study. Overall trends of rainfall increased slightly, but a considerable decrease of monsoon and post-monsoon annual average rainfall was observed at Sylhet; Choudhury et al. 2013 reported decreasing monsoon rainfall for Sylhet region in recent time periods, which is not contradictory to this study. Heavy rainfall will occur in 2024 at Sylhet; this result encourages farmers to grow flood tolerant crops in 2024.

In recent years, relative humidity had increased more at Rajshahi than at Sylhet. So, the climate has changed in terms of relative humidity. Ferdous and Baten (2012) reported that the annual average relative humidity for the period 1961-2010 was found to increase over Rajshahi which supports this study's findings.

Instead of being in a drought prone zone, medium to the rainy condition of future drought analysis indicates no drought in the near future at Rajshahi. It is a relief for farmers of Rajshahi.

At Sylhet, the year 2020, 2025, and 2027 will be considered medium years in most climatic indices, but IhS identified those years as droughty. That means there is less indication for the probability of flood and higher dry conditions; therefore, farmers should be encouraged to plant drought-tolerant crops for those years.

\section{References}

Bari, S.H., M.T.U. Rahman, M.A. Hoque and M.M. Hussain. 2016. Analysis of seasonal and annual rainfall trends in the northern region of Bangladesh. Atmospheric Res. 176: 148-158.

Basak, J.K., R.A.M. Titumir and N.C. Dey. 2013. Climate change in Bangladesh: A historical analysis of temperature and rainfall data. J. Environ. 2(2): 41-46.

Bhuyan, M.D.I., M.M. Islam, and M.E.K. Bhuiyan. 2018. A Trend Analysis of Temperature and Rainfall to Predict Climate Change for North western Region of Bangladesh. Amer. J. Clim. Change 7: 115-134.

Botzan, T.M., M.A. Mariño and A.I. Necula. 1998. Modified de Martonne aridity index: application to the Napa Basin, California. Physical Geography 19(1): 55-70.

Brockwell, P.J. and R.A. Davis. 2016. Introduction to time series and forecasting. Springer, pp. 318-330. 
Temporal variability, trends of climatic variables and drought analysis

Choudhury, S.A., T. Terao, F. Murata and T. Hayashi. 2013. Seasonal variations of temperature and rainfall characteristics in the northeastern part of Bangladesh around Sylhet. J. Agrofor. Environ. 6.

Fahad, M., A. Islam, G. Islam and S.K. Bala, S.K. 2015.The Projection of Temperature and Precipitation over Bangladesh under RCP Scenarios using CMIP5 Multi-Model Ensemble. Proceedings of the International Conference on Recent Innovation in Civil Engineering for Sustainable Development, Gazipur, 11-13 December 2015, WRE-037.

Ferdous, M.G. and M.A. Baten. 2012. Climatic variables of 50 years and their trends over Rajshahi and Rangpur Division. J. Environ. Sci. Nat. Resou. 4(2):147-150.

Karl, T.R., G.A. Meehl, C.D. Miller, S.J. Hassol, A.M. Waple and W.L. Murray. 2008. Weather and Climate Extremes in a Changing Climate. A Report by the U.S. Climate Change Science Program and the Subcommittee on Global Change Re-search, Department of Commerce, NOAAs National Climatic Data Center, Washington DC, pp. 164.

Keka I,A., I. Matin, M. Rahman and D.A. Banu 2012. Analysis of Drought in Eastern Part of Bangladesh, J. Sci. Technol.7: 1.

Kendall, W.S. 1995. A probabilistic model for the variance to mean power law in ecology. Ecol. Modelling 80(2-3):293-297.

Miswan, N., N. Hussin, R. Said, K. Hamzah and E.Z. Ahmad. 2016. ARAR Algorithm in Forecasting Electricity Load Demand in Malaysia. Global J. Pure and Appl. Math. 12(1): 361367.

Nury, A.H., M. Koch and M.J.B. Alam. 2013. Time series analysis and forecasting of temperatures in Sylhet division of Bangladesh. In 4th International Conference on Environmental Aspects of Bangladesh (ICEAB), August, pp. 24-26.

Paul, B.K. 1998.Coping mechanisms practiced by drought victims (1994/5) in North Bengal, Bangladesh. Applied Geography 18: 355-373.

Rajib, M.A., M.M. Rahman, Z.B. Rakib, M.T.H. Khondoker, S.M. Iskander, M.M. Hassan and M.R. Mortuza. 2012. Application of RCM-Based Climate Change Indices in Assessing Future Climate: Part I Temperature Extremes. In: World Environmental and Water Resources Congress 2012: Crossing Boundaries, American Society of Civil Engineers, Reston, 1-7.

Selvaraju, R., A.R. Subbiah, S. Baas and I. Juergens. 2006. Livelihood adaptation to climate variability and change in drought-prone areas of Bangladesh: Developing institutions and options, Asian Disaster Preparedness Center Food and Agriculture Organization of the United Nations, Rome.

Sen, P.K. 1968. Estimates of the regression coefficient based on Kendall's tau. J. Amer. Statist. Assoc. 63(324):1379-1389.

Shahid, S. and H. Behrawan. 2008. Drought risk assessment in the western part of Bangladesh. Nat. Hazards 46: 391-413.

Shitan, M. and Y.L. Ng. 2015. Forecasting the total fertility rate in Malaysia. Pak. J. Statist. 31(5): 547-556.

Solomon, S., D. Qin, M. Manning, Z. Chen, M. Marquis, K.B. Averyt, M. Tignor and H.L. Miller. 2007. Climate Change 2007: The Physical Science Basis: Working Group I Contribution to the Fourth Assessment Report of the IPCC. Cambridge University Press, Cambridge, New York.

Wilhite, D.A. 2000. Drought as a natural hazard: concepts and definitions, in Drought: A Global Assessment, Routledge, London, UK, pp. 3-18.

(Revised copy received 10.11.2020) 